\title{
Fiscal Marksmanship in Pakistan
}

\section{Muhammad Zakaria* and Shujat Ali**}

\begin{abstract}
Using Theil's inequality coefficient based on the mean square prediction error, this paper evaluates the forecasting efficiency of the central government budget and revised budget estimates in Pakistan for the period 1987/88 to 2007/08 and decomposes the errors into biasedness, unequal variation and random components to analyze the source of error. The results reveal that budgetary forecasting is inefficient in Pakistan and the error is due mainly to exogenous variables (random factors). We also find that neither the budget nor revised budget estimates of revenue and expenditure satisfy the criteria of rational expectations of forecasting. Further, there is very little evidence of improvement in the efficiency of budgetary forecasts over time.
\end{abstract}

Keywords: Budget, Forecast errors, Theil's inequality coefficient, rational expectations, Pakistan.

JEL Classifications: C53, E62, H68.

\section{Introduction}

"... the, general principle that no government can hope to execute its economic policies successfully if its budgetary forecasting is wildly inaccurate seems clear enough".

Prest (1975)

The government spends a great deal of time, money and effort in preparing the annual budget. Each department is asked to prepare its budget, which goes through several layers of bureaucracy before it is finally approved. Midway through the year, each department is asked to revise its estimates based on the budget in the first part of the year. Thus, correcting budget estimates is a substantial project. Despite all this, if gross under/over estimates in revenue/spending occur, it reflects a

\footnotetext{
* Assistant Professor, Pakistan Institute of Development Economics, Islamabad, Pakistan.

** Joint Secretary, Ministry of Finance, Islamabad, Pakistan.
} 
failure in budget planning and its implementation, which is termed a failure in fiscal marksmanship by the government. It indicates that the government is not formulating budget estimates efficiently on the basis of all the available information. In other words, the government is not making budget estimates on the basis of rational expectations.

In an efficient market, economic agents make predictions on the basis of rational expectations. The rational expectations hypothesis stipulates that economic agents use all available information efficiently to form expectations about future economic conditions. In the literature, the rational expectations hypothesis has been used to form predictions about various macroeconomic indicators, such as gross domestic product (GDP), inflation, and unemployment, etc. However, little effort has been devoted to efficient forecasts of the budget and its components (revenue and expenditure) using rational expectations, particularly, in developing countries, ${ }^{1}$ where the wide variations in budgetary forecast errors have significant macroeconomic implications. First, significant variations between actual revenue and expenditure from the predicted budgetary magnitudes can indicate the nonoptimization or nonattainment of the set objectives of fiscal policy. Second, excessive financing of deficits occurs if actual expenditure exceeds forecasted expenditure and cutbacks in crucial public expenditure result when actual revenue falls short of budgeted. Third, a budget represents a key link between the formulation and implementation of five-year plans; without sound budgetary forecasts, a satisfactory integration between plan formulation and implementation cannot be achieved. Fourth, persistently larger-thanbudgeted expenditures, a good proportion of which are unplanned, result in the poor integration of plans with budgetary policy, which creates distortions in the implementation of government plans. Fifth, large errors in forecasting fiscal variables weaken the credibility of the central government and fiscal discipline in the country. Without strong fiscal discipline, it is difficult to see how discipline in other areas, so vital for development, can be instilled.

Errors in budgetary forecasting can occur due to endogenous and exogenous factors. Errors due to endogenous factors can arise because of the use of incorrect parameters, especially with respect to prices, incomes, and elasticities of demand and supply of products and factors in the case of the forecasting authorities' failure to take into account the two-way

${ }^{1}$ Fiscal marksmanship studies for developed countries are relatively few and on the whole are not very recent. 
relationship between the government budget and national income, etc. Exogenous factors are those that are beyond the control of the forecasting authorities, e.g., a sudden change in the terms of trade, unavailability of external loans and grants, an outbreak of international conflict, unforeseen climatic conditions, international developments such as the quadrupling of oil prices after $9 / 11$, a sudden shift in the internal political situation in the country, etc. ${ }^{2}$

Previously, Prest (1961), Allan (1965), and Davis (1980) studied the accuracy of budget forecasts in the context of the UK and concluded that accurate budget forecasts are needed if fiscal policy is to be used to move the economy toward full employment without engendering excessive inflation. Similarly, Auld (1970) has investigated forecasting errors in budgetary estimates in the context of Canada, Bird (1970) for Colombia, Rabushka (1976) for Hong Kong, Asher (1977) for Singapore, Morrison (1986) for the US, and Bagdigen (2005) for Turkey. More recently, Chakraborty and Sinha (2008) have tested budgetary forecasts and their efficiency for India for the period 1990/91 to 2003/04. ${ }^{3}$ The study concludes that neither revenue nor expenditure forecasts in India are rational. The present paper examines the accuracy of the Government of Pakistan's budgetary forecasts for the period 1987/88 to 2007/08. The evaluation is done in terms of errors and their decomposition, unbiasedness, rational expectations, and improvement/deterioration in forecasting efficiency over time. The importance of good fiscal marksmanship makes it all the more surprising that no work has been done on the Pakistan experience. There have been a few discussions on the significance of budget errors, but no study has been made of the discrepancies between budget estimates and outturns as such. Thus, this study fills the gap in the literature on the subject in Pakistan.

The rest of the paper is organized as follows: Section 2 provides an analytical framework. Section 3 presents an overview of the data and discusses empirical results. Section 4 concludes the paper and discusses policy implications.

\footnotetext{
${ }^{2}$ Because of the interdependence of endogenous and exogenous sources of error, it is difficult to systematically isolate the influence of each of these sources of error and no such attempt is made in this paper. Instead, the paper focuses on examining the direction and magnitude of errors in forecasting the components of the budget.

${ }^{3}$ Earlier studies on fiscal marksmanship in India include Chand (1962), Asher (1978), Chakrabarty and Varghese (1982), and Bhattacharya and Kumari (1988).
} 


\section{Analytical Framework}

Budget estimates of government revenue and expenditure can be regarded as budget forecasts of actual government revenue and expenditure, respectively. If $A_{t}$ is the actual value and $P_{t}$ the predicted value in year $t$ then the forecasting error $\left(E_{t}\right)$ in percentage form can be calculated as

$$
E_{t}=\left[\left(P_{t}-A_{t}\right) / A_{t}\right] 100
$$

$E_{t}$ can be positive, negative, or 0 depending on whether the forecast is overpredicted, underpredicted, or perfect. Apart from such percentage errors, several other statistics such as mean errors and root mean square errors (RMSEs) are frequently used to evaluate prediction performance. The problem with mean errors is that they may be close to 0 if large positive errors cancel out large negative errors. Although mean absolute errors can be used to avoid the problem of positive and negative errors canceling each other out, RMSEs are used more often in practice, since they penalize large individual errors more heavily. ${ }^{4}$ The RMSE and root mean square percentage error (RMSPE) for a sample period of $n$ years are calculated with the help of the following formulas, respectively.

$$
\begin{aligned}
& R M S E=\sqrt{1 / n \sum\left(P_{t}-A_{t}\right)^{2}} \\
& R M S P E=\sqrt{1 / n \sum\left[\left(P_{t}-A_{t}\right) / A_{t}\right]^{2}}
\end{aligned}
$$

The RMSE will be zero when the forecast is absolutely perfect for all years, i.e., when the predicted value is equal to the actual value for all $t$. A more rigorous measure for analyzing the accuracy of budget forecasts is Theil's (1958) inequality coefficient (U), which is defined as

$$
U_{1}=\frac{\sqrt{1 / n \sum\left(P_{t}-A_{t}\right)^{2}}}{\sqrt{1 / n \sum P_{t}^{2}}+\sqrt{1 / n \sum A_{t}^{2}}}
$$

\footnotetext{
4 The RMSE has two limitations. It does not distinguish between under- and overpredictions. Also, there is no theoretical upper bound for the RMSE, and consequently it cannot be used for statistical inference.
} 
The numerical value of $U_{1}$ falls between 0 and 1 . If $U_{1}$ is close to 0 , it means that there is a perfect fit (in this case $P_{t}=A_{t}$ for all observations). If $U_{1}$ is close to unity, it means that there is nonpositive proportionality between $P_{t}$ and $A_{t}$ (in this case $P_{t} \neq A_{t}$ for all observations). Alternatively, Theil's $(1966,1971)$ revised measure of inequality is defined as

$$
U_{2}=\frac{\sqrt{1 / n \sum\left(P_{t}-A_{t}\right)^{2}}}{\sqrt{1 / n \sum A_{t}^{2}}}
$$

This measure has the advantage that the inequality coefficient does not depend on the forecast as the denominator does not contain $P_{t}$. If the forecast is perfect, then $U_{2}$ equals 0 . However, there is no upper bound value for $U_{2}$. If $P_{t}$ and $A_{t}$ are defined in terms of changes, then no change forecast $\left(P_{t}=0\right.$ for all $\mathrm{t}$ ) would lead to a value of 1 . When $U_{2}$ equals unity, the forecast has the same accuracy as would have been achieved by means of a "naïve no change extrapolation" (Theil, 1971). A more precise measure of Theil's inequality statistic is also used by incorporating the lags in the actuals and the difference of predicted value from the lag of the actuals to capture the magnitude of error. Mathematically,

$$
U_{3}=\frac{\sqrt{1 / n \sum[p(t)-a(t)]^{2}}}{\sqrt{1 / n \sum[p(t)]^{2}}+\sqrt{1 / n \sum[a(t)]^{2}}}
$$

where $a(t)=A(t)-A(t-1)$ and $p(t)=P(t)-A(t-1)$. The upper value of $U_{3}$ would depend on whether or not the direction of change is predicted correctly. If the direction of change is predicted correctly, on average, i.e., when $\sum[p(t) \cdot a(t)]>0$, then $U_{3}$ will be less than unity. If, on the other hand, the direction of change is predicted wrongly, i.e., when $\sum[p(t) \cdot a(t)]<0$, then $U_{3}$ will be greater in unity. $U_{3}$ will be exactly equal to unity when the forecast implies no change, i.e., when $p(t)=0$ for all $t$ or $\sum[p(t) \cdot a(t)]=0.5$

5 There is no specific probability distribution of Theil's inequality coefficient and consequently it cannot be used for statistical inference except as a broad measure of prediction. In addition, like the RMSE, it cannot distinguish between under- or overprediction. 
Furthermore, we also analyze the partitioned forecast error of budgetary estimates. For this purpose, the mean square prediction error is decomposed to obtain systematic and random sources of error. The systematic portion is further separated into the proportion of the total forecast error due to bias and the proportion of total forecast error due to unequal variation (Morrison, 1986). It is pertinent to mention that both systematic and random sources of error add up to unity. Mathematically,

$$
\frac{\left(\overline{P_{t}}-\overline{A_{t}}\right)^{2}}{1 / n \sum\left(P_{t}-A_{\tau}\right)^{2}}+\frac{\left(S_{p}-S_{a}\right)^{2}}{1 / n \sum\left(P_{t}-A_{\tau}\right)^{2}}+\frac{2(1-r) S_{p} \cdot S_{a}}{1 / n \sum\left(P_{t}-A_{t}\right)^{2}}=1
$$

where $\bar{P}_{t}$ and $\overline{A_{t}}$ are mean predicted and mean actual changes, respectively, $S_{p}$ and $S_{a}$ are the standard deviations of predicted and actual values, respectively, and $r$ is the coefficient of correlation between predicted and actual values. The first expression on the left hand side of equation (7) is the proportion of the total forecast error due to bias. It represents a measure of proportion of error due to the over/underprediction of the average value. The second expression on the left hand side of equation (7) is the proportion of total forecast error attributable to unequal variation. In other words, it measures the proportion of error due to the over/underprediction of the variance of the values. The third expression on the left hand side of equation (7) measures the proportion of forecast error due to random variation. The first two sources of error are systematic. Presumably, they can be reduced by improved forecasting techniques, while the random component is beyond the control of the forecaster (Theil, 1966; Pindyck and Rubenfield, 1998).

Budget estimates can be viewed as government expectations of revenue, expenditure, and deficit. Expectations are derived both endogenously and rationally. If expectations are derived endogenously then the forecast is based on univariate autoregressive behavior. In this case $P_{t}$ becomes some function of $A_{t-1}, A_{t-2}$ and so on. If expectations are rational, then forecasts of government revenue, expenditure, etc., will depend on prior information on all variables such as national income, price level, etc., which have functional relationships with government revenues and expenditures. ${ }^{6}$

\footnotetext{
${ }^{6}$ In practice, budget estimates may be based on both endogenous and rational expectations because estimates are made partly on the basis of past trends of revenues and expenditures and partly on the basis of expected national income, imports, inflation rate, etc.
} 
This paper also tests the rational expectation hypothesis for fiscal variables in Pakistan. For this, a necessary condition is that the forecast should be an unbiased predictor of the actual (Muth, 1961). The sufficient condition is that the forecast error is uncorrelated with the predicted value, which implies that the correlation coefficient $(\rho)$ between the forecast error and predicted value should be 0 , i.e. $\rho=0$ (Muth, 1961). In other words, the sufficient condition is that the predicted error must be uncorrelated with historical information, which can be tested in terms of whether or not the lagged value of the actuals is related to the present value of actuals (Lovell, 1986). Thus, the rational expectations hypothesis can be tested with the help of the following equation.

$$
A_{t}=\beta_{1}+\beta_{2} P_{t}+\beta_{3} A_{t-1}+v_{t}
$$

As defined previously, $A_{t}$ is the actual value and $P_{t}$ is the predicted value. The condition for rational expectations is satisfied if $\beta_{1}=0, \beta_{2}=1, \beta_{3}=0$ and $\rho=0$.

We also examine whether or not the efficiency of budgetary forecasts improves over time. This can be examined by estimating the following function.

$$
E_{t}=\alpha_{1}+\alpha_{2} T_{t}+v_{t}
$$

As defined previously $E_{t}=\left[\left(P_{t}-A_{t}\right) / A_{t}\right] 100$ and $\mathrm{T}$ is the linear time trend. The efficiency of forecasting improves if $\alpha_{2}<0$. In turn, $0<\alpha_{2}$ would imply deterioration in forecasting efficiency over time.

\section{Data and Budgetary Forecasts}

Budgetary data in Pakistan is published in three stages: (i) as budget estimates, (ii) as revised estimates, and (iii) as actuals. The difference between budget estimates and revised estimates is that, while the former represents estimates of revenue and expenditure for the next fiscal year, the latter refers to estimates for the current fiscal year. In fact, revised estimates incorporate all modifications in budget estimates and utilize actual figures for part of the financial year, usually eight or nine months. Revised estimates are therefore partly actual and partly forecasted. Both budget and revised estimates are categorized into

revenue and capital accounts. The final estimates, given as actuals, are 
published a year after the completion of the financial year for which it was prepared. The fiscal year in Pakistan is from 1 July to 30 June, and the budget is presented in early June.

For this study, annual time series data was collected for revenue and expenditure for Pakistan for the period 1987/88 to 2007/08. While $2007 / 08$ represents the latest year for which relevant data is available, due to several changes in accounting classifications, mergers, and regroupings of items, consistent data for the years before 1987/88 could not be obtained. Thus, the choice of time period was governed by the availability of consistent time series data. Due to the unavailability of budget documents, we relied primarily on the Budget Wing of the Ministry of Finance, Islamabad. ${ }^{7}$

Some summary statistics regarding forecasting accuracy for revenues and expenditures are presented in Table-1 and Table-2, respectively. The tables present the actual values of both revenue and expenditure along with the forecasting errors for the sample period. The results reveal that both revenue and expenditure components of the budget have errors in forecast. The analysis shows that revenue receipts were broadly overestimated during the 1990s both for budget and revised estimates. This indicates that the government had given high targets of revenue collection to the Federal Board of Revenue (FBR), ${ }^{8}$ which the FBR was unable to collect due to shortfalls in revenues from income tax and import and excise duties. This shortfall was mainly due to recessionary conditions in the industrial sector and the changing composition of imports toward lower or no duty imports. Further, many of the factors affecting revenues from customs duties (world prices of imported goods, availability of external assistance.) are notoriously difficult to predict. The forecasting errors seem to be large. Revenue receipts were grossly underestimated during the 2000s both for budget and revised estimates, mainly due to uncertainty in obtaining foreign aid and assistance to fight terrorism and the shortfall of revenues from earthquake-affected areas in 2005. In turn, errors in capital receipts have shown a somewhat mixed trend during the 1990s and 2000s both in budget and revised estimates. Errors in capital receipts were mainly errors in forecasting defense expenditures, interest payments, and grants/aid. On the expenditure side, errors in revenue expenditures showed a varied tendency during the 1990s both in budget

\footnotetext{
${ }^{7}$ Appendix Table 1 presents data on revenue and capital receipts in the revenue account, while Appendix Table 2 explains data on revenue and capital receipts in the expenditure account.

${ }^{8}$ Formerly the Central Board of Revenue.
} 
and revised estimates, but during the 2000s revenue expenditures were grossly underestimated with respect to budget estimates (due mainly to low expected expenditures on the reconstruction and rehabilitation of earthquake-affected areas) and were grossly overestimated in the case of revised estimates (due to high expectations of obtaining assistance from donors to be used for the uplift of earthquake-hit territories). Like capital receipt errors, errors in capital expenditures also showed a slightly mixed trend during the 1990s and 2000s both in budget and revised estimates. The errors in capital expenditures were due mainly to errors in forecasting loans and advances.

Table 1: Errors in Forecasting Revenue

(Rs. Billion)

\begin{tabular}{lcccccccc}
\hline & \multicolumn{3}{c}{ Revenue Receipts } & & \multicolumn{3}{c}{ Capital Receipts } \\
\cline { 2 - 4 } \cline { 7 - 8 } Years & Actual & \% Error & \% Error & & \multicolumn{3}{c}{$\%$ Error } & $\%$ Error \\
\hline $1987-88$ & 119.60 & -0.57 & 1.37 & & 642.44 & -8.99 & -5.41 \\
$1988-89$ & 143.08 & 2.14 & 0.30 & & 729.86 & -11.58 & 1.97 \\
$1989-90$ & 163.53 & -2.50 & -1.48 & & 811.63 & -5.90 & -0.64 \\
$1990-91$ & 170.34 & 8.79 & 8.18 & & 914.17 & 6.18 & -6.75 \\
$1991-92$ & 216.59 & 6.46 & 2.90 & & 864.44 & -16.61 & -12.28 \\
$1992-93$ & 242.62 & 7.58 & 2.98 & & 947.00 & 5.94 & 0.94 \\
$1993-94$ & 273.24 & 5.66 & 6.92 & & 1071.51 & 1.29 & 2.98 \\
$1994-95$ & 321.32 & 12.71 & 0.95 & & 1171.12 & -3.45 & -0.98 \\
$1995-96$ & 370.51 & 3.26 & 3.08 & & 1371.44 & -6.94 & -3.26 \\
$1996-97$ & 384.26 & 18.17 & 1.16 & & 1505.84 & -1.18 & -1.01 \\
$1997-98$ & 433.64 & 6.08 & 3.58 & & 1653.07 & 3.50 & 2.08 \\
$1998-99$ & 464.37 & 11.65 & 8.07 & & 1888.77 & 1.63 & 2.47 \\
$1999-00$ & 531.30 & 5.58 & -2.24 & & 2136.14 & -14.57 & 0.18 \\
$2000-01$ & 535.09 & 11.12 & 4.27 & & 2572.58 & -8.05 & -1.97 \\
$2001-02$ & 619.07 & 4.00 & 2.22 & & 2733.45 & 4.38 & 1.16 \\
$2002-03$ & 720.70 & -6.36 & -2.65 & & 2304.84 & 2.35 & -1.40 \\
$2003-04$ & 794.13 & -8.28 & -4.17 & & 2071.16 & -5.54 & -1.59 \\
$2004-05$ & 900.04 & -11.52 & -2.75 & & 3115.29 & -26.33 & -1.08 \\
$2005-06$ & 1076.63 & -13.86 & -5.01 & & 3228.64 & 3.03 & -1.06 \\
$2006-07$ & 1297.96 & -16.58 & -6.47 & & 3764.30 & -17.62 & -0.93 \\
$2007-08$ & 1499.38 & -8.75 & -6.70 & & 3897.15 & -4.66 & -0.92 \\
\hline
\end{tabular}

Note: BE (RE) is Budget Estimates (Revised Estimates). 
Overall, errors in budget estimates both in revenue and capital receipts are far greater then errors in revised estimates. This indicates that the government made errors at the time of budget formulation but there was ample opportunity to correct these errors when the budget estimates were revised. Thus, the errors grew smaller in revised estimates. Further, in relative terms, errors in budget forecasting were greater during the 2000s than during the 1990s both in revenue and capital receipts, particularly in relation to budget estimates. A similar interpretation holds for errors in forecasting expenditures. The disaggregated level of analysis also indicates that the degree of error in forecasting receipts is more or less the same as errors in forecasting expenditures during the sample period. Thus, we can conclude that the forecasting record of both revenue and expenditure accounts with respect to both budget and revised estimates are far from satisfactory. However, errors are not systematic, which indicates that revenue and expenditure forecasts in Pakistan are not based on adaptive expectations.

Table 2: Errors in Forecasting Expenditures

\begin{tabular}{|c|c|c|c|c|c|c|}
\hline \multirow[b]{2}{*}{ Years } & \multicolumn{3}{|c|}{ Revenue Expenditures } & \multicolumn{3}{|c|}{ Capital Expenditures } \\
\hline & Actual & $\begin{array}{c}\text { \% Error } \\
\text { (BE) }\end{array}$ & $\begin{array}{c}\text { \% Error } \\
\text { (RE) }\end{array}$ & Actual & $\begin{array}{c}\text { \% Error } \\
\text { (BE) }\end{array}$ & $\begin{array}{c}\text { \% Error } \\
\text { (RE) }\end{array}$ \\
\hline $1987-88$ & 147.54 & -8.75 & -0.89 & 51.15 & 12.26 & 6.08 \\
\hline 1988-89 & 163.09 & -0.02 & -2.21 & 47.03 & -10.89 & 2.06 \\
\hline $1989-90$ & 165.24 & 0.52 & 5.31 & 57.18 & 4.69 & 1.05 \\
\hline 1990-91 & 189.28 & -2.00 & -2.77 & 70.86 & -22.30 & -15.52 \\
\hline 1991-92 & 211.69 & -3.88 & 0.64 & 114.40 & -20.78 & -11.19 \\
\hline $1992-93$ & 248.54 & -5.70 & 0.31 & 86.14 & 9.20 & -2.29 \\
\hline 1993-94 & 268.03 & 1.65 & 6.72 & 96.30 & -7.66 & 3.23 \\
\hline 1994-95 & 315.71 & 0.14 & 0.48 & 106.05 & 2.15 & 0.74 \\
\hline $1995-96$ & 382.67 & -4.76 & -0.79 & 124.20 & -7.29 & -10.89 \\
\hline 1996-97 & 414.45 & 1.20 & 0.27 & 135.38 & 2.36 & -0.57 \\
\hline 1997-98 & 466.50 & 2.24 & 0.80 & 125.90 & 0.56 & 3.20 \\
\hline 1998-99 & 529.03 & -2.47 & -6.58 & 156.98 & 2.50 & -4.64 \\
\hline 1999-00 & 604.37 & -8.35 & -3.18 & 137.07 & 10.53 & 10.70 \\
\hline 2000-01 & 612.68 & -1.41 & -1.79 & 95.38 & -5.30 & 0.79 \\
\hline 2001-02 & 694.45 & -4.59 & 0.46 & 254.28 & -31.78 & 1.94 \\
\hline $2002-03$ & 705.84 & -8.29 & 0.47 & 155.41 & -21.85 & -2.20 \\
\hline 2003-04 & 769.70 & -8.47 & 0.45 & 122.99 & 0.22 & 1.92 \\
\hline 2004-05 & 833.82 & -5.71 & 0.43 & 150.65 & -18.93 & -1.08 \\
\hline 2005-06 & 1068.50 & -10.05 & 0.35 & 123.01 & 7.75 & 0.92 \\
\hline 2006-07 & 1230.28 & -9.29 & 0.31 & 131.11 & 5.12 & -0.59 \\
\hline 2007-08 & 1767.56 & -23.42 & 0.23 & 148.59 & 4.56 & 0.36 \\
\hline
\end{tabular}

Note: BE (RE) is Budget Estimates (Revised Estimates). 
The RMSE and RMSPE of revenues and expenditures are given in Table-3. As expected, both the RMSE and RMSPE turn out to be lower for revised budget estimates in comparison to budget estimates. RMSEs indicate that, in relative terms, the capital budget reveals more forecasting errors than the revenue budget. In other words, capital receipts and capital expenditures showed relatively more forecasting errors than revenue receipts and revenue expenditures during the sample period. However, capital expenditures have shown less errors then revenue expenditures in the budget and revised estimates in the case of the RMSE alone. This result shows that the efficiency of budgetary estimates for revenue receipts and expenditures has improved over time, because it might show an improvement in the budget estimation process, especially since revenue receipts and expenditures far outweigh capital receipts and expenditures. The results also indicate that more emphasis needs to be placed on predicting the budget's capital account. The RMSPEs for budget estimates and actuals are higher than those for revised estimates and actuals, which again indicates that budget forecasts in Pakistan are less efficient. Although the size of the errors is small, even relatively small errors in forecasting revenue and expenditure can cause large errors in estimates of the budget deficit and as a result in the government's borrowing requirements.

Table 3: Root Mean Square Errors for Federal Budget Forecasting

\begin{tabular}{llccc}
\hline & $\begin{array}{c}\text { RMSE (BE, } \\
\text { Actual) }\end{array}$ & $\begin{array}{c}\text { RMSPE } \\
\text { (BE, } \\
\text { Actual) }\end{array}$ & $\begin{array}{c}\text { RMSE (RE, } \\
\text { Actual) }\end{array}$ & $\begin{array}{c}\text { RMSPE } \\
\text { (RE, } \\
\text { Actual) }\end{array}$ \\
\hline Revenue Receipts & 75.38 & 0.09 & 34.80 & 0.04 \\
Capital Receipts & 256.40 & 0.10 & 40.17 & 0.04 \\
Revenue Expenditures & 100.14 & 0.07 & 10.39 & 0.03 \\
Capital Expenditures & 21.86 & 0.13 & 6.27 & 0.06 \\
\hline
\end{tabular}

Note: RMSE (RMSPE) is Root Mean Square Error (Root Mean Square Percentage Error) and BE (RE) is Budget Estimates (Revised Estimates).

Based on RMSEs, we calculate Theil's inequality coefficient (U). Like RMSEs, Theil's inequality coefficient cannot distinguish between under- or overprediction. However, the magnitude of errors can be assessed from the inequality coefficients (Us). The three inequality coefficients, estimated using variants of Theils' $U$, are given in Table-4. The table reveals that Theil's inequality coefficients for budget estimates and actuals are higher than those for revised estimates and actuals. Even the value of Theil's 
inequality coefficient $\left(U_{3}\right)$ goes up to 0.503 in relation to budget estimates and actuals for capital receipts, which supports our previous finding that forecasts of budget estimates are inefficient in Pakistan and more emphasis should be placed on predicting the budget's capital account.

Table 4: Theil's Inequality Statistic (U) for Federal Budget Forecasting

\begin{tabular}{lccccccc}
\hline & \multicolumn{3}{c}{ Theil's U (BE, Actual) } & & \multicolumn{3}{c}{ Theil's U (RE, Actual) } \\
\cline { 2 - 3 } \cline { 6 - 8 } & $\mathrm{U}_{1}$ & $\mathrm{U}_{2}$ & $\mathrm{U}_{3}$ & & $\mathrm{U}_{1}$ & $\mathrm{U}_{2}$ & $\mathrm{U}_{3}$ \\
\hline Revenue Receipts & 0.059 & 0.115 & 0.217 & & 0.027 & 0.053 & 0.118 \\
Capital Receipts & 0.062 & 0.121 & 0.503 & & 0.009 & 0.019 & 0.071 \\
Revenue Expenditure & 0.077 & 0.145 & 0.311 & & 0.008 & 0.015 & 0.043 \\
Capital Expenditure & 0.090 & 0.172 & 0.343 & & 0.025 & 0.049 & 0.094 \\
\hline
\end{tabular}

Note: BE (RE) is Budget Estimates (Revised Estimates).

Until now we have seen that there are errors in budget forecasting in Pakistan. An important question is, what accounts for errors in budget forecasting in Pakistan. To answer this question, we decompose errors into two components: errors on account of miscalculation and wrong judgment (bias and variance errors), and errors on account of unanticipated and exogenous shocks (random errors). The former can occur partly because of incorrect judgment of key economic variables such as national income, investment, savings, inflation, which influences government revenues and expenditures; and partly because of improper estimation of key parameters of budgeting, such as tax and expenditure elasticities. The latter is beyond the control of the government. Table- 5 provides estimates of these error components.

The decomposition of error reveals that, in relative terms, the proportion of error due to random variations has been significantly higher, leaving less scope for the elimination of error. However, the role of errors due to bias and variance proportion cannot be ignored in budget estimates (compared to revised estimates). Although the proportion of error in the forecast due to bias and unequal variation is relatively low, better forecasts based on the buoyancy estimates of revenue and expenditure as well as periodic assessment of the stochastic errors of the budgetary forecast might improve the efficiency and reliability of budgetary forecasting. The analysis has shown that there are errors in budget forecasts in Pakistan but that this is mainly due to random variations, which is beyond the control of the government. These figures 
are not standardized and hence no rigorous inference can be drawn from them. Therefore, the efficiency and accuracy of budget forecasts is tested using the rational expectations hypothesis.

Table 5: Partitioning Error Components

\begin{tabular}{|c|c|c|c|c|c|c|}
\hline & \multicolumn{6}{|c|}{ Decomposition of Forecasting Errors } \\
\hline & \multicolumn{3}{|c|}{ Budget Estimates } & \multicolumn{3}{|c|}{ Revised Estimates } \\
\hline & Bias & Variance & Random & Bias & Variance & Random \\
\hline Revenue & & & & & & \\
\hline Receipts & 0.044 & 0.561 & 0.395 & 0.056 & 0.665 & 0.279 \\
\hline Capital & & & & & & \\
\hline Receipts & 0.141 & 0.121 & 0.738 & 0.144 & 0.003 & 0.853 \\
\hline $\begin{array}{l}\text { Revenue } \\
\text { Expenditure }\end{array}$ & 0.203 & 0.552 & 0.245 & 0.007 & 0.007 & 0.986 \\
\hline $\begin{array}{l}\text { Capital } \\
\text { Expenditure }\end{array}$ & 0.100 & 0.113 & 0.787 & 0.015 & 0.035 & 0.950 \\
\hline
\end{tabular}

Table- 6 presents the estimated results of the rational expectation hypothesis. ${ }^{9}$ The results reveal that coefficients of $\beta_{1}$ are not significant in most cases and $\beta_{2}$ is not significantly different from 1 . It also reveals that revenue expenditure seems to be overestimated by a constant amount every year in budget estimates and actuals, which is reflected in $\beta_{1}<0$. Similarly, revenue receipts in revised estimates and actuals seem to be overestimated by a fixed rate, as $\beta_{1}<0$. In relation to budget estimates, capital receipts are overestimated (as $\left.\beta_{2}<1\right)$, while both revenue and capital expenditures seem to be underestimated (as $\beta_{2}>1$ ). Revised estimates systematically overestimate both revenue and capital receipts as well as revenue and capital expenditures (as $\beta_{2}<1$ ). These results suggest that neither budget estimates nor revised budget estimates are the product of rational expectations of actual government receipts and expenditures.

It is also worth noting that the coefficients of $\beta_{3}$ are not insignificant in all cases. Similarly, the high values of $\rho$ signify that the forecast errors of receipts and expenditures are correlated with the

${ }^{9}$ The stationary properties of the variables are not checked because the purpose is not to find a cointegrated relationship among the variables. 
respective budget forecasts. Thus, the coefficients in Table- 6 suggest that the rational expectations hypothesis is not valid in the case of fiscal variables in Pakistan during the sample period as neither the necessary condition for rational expectations (i.e., that the forecast should be an unbiased predictor of actuals) nor the sufficient condition for rational expectations (i.e., that the predicted error must be uncorrelated with the historical information) are fulfilled.

The overall goodness of fit of both budget estimates and revised estimates predictions, as indicated by $\mathrm{R}^{2}$, is quite satisfactory. The values of Durbin $h$ statistics are less than $|1.96|$, which indicates that least square estimations lead to errors that are serially correlated. This suggests that (strong) rationality can be rejected, because information that was available when the prediction was made (the previous forecast error) was not being taken into account. Therefore, in the presence of an autocorrelation error, inferences based on the least square estimation should be viewed with caution. We do not regard these results as evidence that econometric forecasting methods are useless. It could be that government in Pakistan implements these methods poorly, and/or that the results are ignored by political decision makers, and/or that for reasons fiscal variables have become intrinsically more difficult to forecast, so that in the absence of econometric methods, the results would have been worse. Still, on the basis of these results, one would have to be cautious in urging the government to replace old hands with computers. 
Table 6: Testing Rational Expectations

\begin{tabular}{lccccccc}
\hline Variables & $\beta_{1}$ & $\beta_{2}$ & $\beta_{3}$ & $\mathrm{R}^{2}$ & Adj. R & Durbin $h$ & $\rho$ \\
\hline Revenue & -6.987 & -0.159 & 1.331 & 0.995 & 0.994 & -1.050 & -0.734 \\
Receipts & $(-0.406)$ & $(-0.761)$ & $(6.450)^{*}$ & & & & \\
Capital & -7.245 & 0.897 & 0.173 & 0.947 & 0.940 & NA & -0.266 \\
Receipts & $(-0.058)$ & $(2.998)^{*}$ & $(0.589)$ & & & & \\
Revenue & -76.874 & 1.672 & -0.472 & 0.984 & 0.982 & NA & -0.801 \\
Expenditure & $(-3.197)^{*}$ & $(4.757)^{*}$ & $(-1.266)$ & & & & \\
Capital & 0.609 & 1.124 & -0.062 & 0.770 & 0.743 & 1.900 & -0.172 \\
Expenditure & $(0.034)$ & $(6.548)^{*}$ & $(-0.469)$ & & & & \\
& \multicolumn{7}{c}{ (Revised Estimates, Actuals) } \\
Revenue & -35.540 & 0.959 & 0.136 & 0.998 & 0.997 & NA & -0.834 \\
Receipts & $(-3.932)^{*}$ & $(4.628)^{*}$ & $(0.606)$ & & & & \\
Capital & 9.098 & 0.979 & 0.027 & 0.999 & 0.998 & 1.021 & -0.043 \\
Receipts & $(0.469)$ & $(31.712)^{*}$ & $(0.819)$ & & & & \\
Revenue & -0.220 & 0.971 & 0.036 & 0.999 & 0.999 & 1.334 & 0.092 \\
Expenditure & $(-0.042)$ & $(30.840)^{*}$ & $(0.861)$ & & & & \\
Capital & 7.257 & 0.964 & -0.016 & 0.981 & 0.979 & -0.435 & 0.248 \\
Expenditure & $(1.538)$ & $(26.566)^{*}$ & $(-0.457)$ & & & & \\
\hline
\end{tabular}

Note: Values in parentheses denote underlying student- $t$ values. The $t$ statistics significant at $5 \%$ level of significance are indicated by *.

Table 7 provides the results of the efficiency of budget forecasts. The results suggest that not all the variables have improved significantly over time. Only the forecasts of revenue receipts and expenditures in budget estimates and revenue receipts in revised estimates have shown a significant improvement over time. These results support the hypothesis that the efficiency of budgetary forecasts seems to have remained unchanged during the sample period in Pakistan. 
Table 7: Efficiency of Budgetary Forecasts

\begin{tabular}{|c|c|c|c|c|c|}
\hline & $\alpha_{1}$ & $\alpha_{2}$ & $\mathrm{R}^{2}$ & Adj. $R^{2}$ & DW \\
\hline & \multicolumn{5}{|c|}{ (Budget Estimates, Actuals) } \\
\hline \multirow[t]{2}{*}{ Revenue Receipts } & 10.159 & -0.850 & 0.311 & 0.274 & 0.825 \\
\hline & $(2.990)^{*}$ & $(-2.925)^{*}$ & & & \\
\hline \multirow[t]{2}{*}{ Capital Receipts } & -3.190 & -0.172 & 0.015 & -0.037 & 2.471 \\
\hline & $(-0.848)$ & $(-0.535)$ & & & \\
\hline \multirow[t]{2}{*}{ Revenue Expenditure } & 0.645 & -0.547 & 0.340 & 0.306 & 1.233 \\
\hline & $(0.316)$ & $(-3.131)^{*}$ & & & \\
\hline \multirow[t]{3}{*}{ Capital Expenditure } & -4.082 & 0.004 & 0.000 & -0.053 & 1.781 \\
\hline & $(-0.749)$ & $(0.008)$ & & & \\
\hline & \multicolumn{5}{|c|}{ (Revised Estimates, Actuals) } \\
\hline \multirow[t]{2}{*}{ Revenue Receipts } & 4.970 & -0.428 & 0.363 & 0.330 & 1.604 \\
\hline & $(3.273)^{*}$ & $(-3.294)^{*}$ & & & \\
\hline \multirow[t]{2}{*}{ Capital Receipts } & -2.708 & 0.140 & 0.063 & 0.013 & 1.639 \\
\hline & $(-1.866)$ & 1.126 & & & \\
\hline \multirow[t]{2}{*}{ Revenue Expenditure } & 0.305 & -0.035 & 0.007 & -0.046 & 2.004 \\
\hline & $(0.262)$ & $(-0.353)$ & & & \\
\hline \multirow[t]{2}{*}{ Capital Expenditure } & -2.478 & 0.172 & 0.033 & -0.018 & 1.688 \\
\hline & $(-0.991)$ & $(0.802)$ & & & \\
\hline
\end{tabular}

Note: Values in parentheses denote underlying student- $t$ values. The $t$ statistics significant at $5 \%$ level of significance are indicated by *.

\section{Conclusion}

This paper attempts to examine the magnitude of error in the budget estimates and revised estimates of the Government of Pakistan's revenues and expenditures for the period 1987/88 to 2007/08. For this purpose, we have calculated simple percentage errors, RMSEs, and Theil's inequality coefficient. To analyze the source of errors, errors have been decomposed into biasedness, unequal variation, and random components. Further, to test rationality in the budget forecasts, we also present a rational expectations hypothesis.

The results show that the degree of error in forecasting revenues is more or less the same as errors in forecasting expenditures, and that the capital budget reveals more forecasting errors than the revenue budget. 
However, there is no specific trend in forecasting errors, which reveals that budgetary estimates in Pakistan are not made based on adaptive expectations. In other words, the results indicate that there is no simple way to characterize the nature of the bias. Forecasters do not always under/overforecast by the same number of percentage points; nor do they under/overforecast by a constant proportion of the correct forecast. Hence, there does not appear to be a simple rule of thumb producing the discrepancy between actual and predicted forecasts. Values of Theil's inequality coefficients also show unfairness in budget forecasts in Pakistan. The proportion of error due to random variations is relatively higher, which is beyond the control of the forecaster, while errors due to bias and variance are low, which again shows inefficiency in budget forecasting in Pakistan. The test of rational expectations is not validated, thereby discouraging the applicability of the rational expectations hypothesis in fiscal estimates in Pakistan. The efficiency of forecasts has also not shown a general improvement in budgeting over time.

The analysis in this paper indicates that there is a great deal of room for improvement in the Government of Pakistan's fiscal marksmanship. There are two ways of improving the efficiency and reliability of budget estimates of government revenue and expenditure: (i) having better forecasts of basic macro variables, such as national income, price level, etc., and (ii) having better estimates of key parameters such as tax and expenditure elasticities. Both these require an increase in the technical sophistication of the forecasting process. Additionally, the government should focus on those areas of its revenues and expenditures which it can forecast most accurately. The areas of greatest predictability on the revenue side, for instance, are income tax, excise duty, and general sales tax; on the expenditure side, are, for instance, civil and defense expenditures. Further, to reduce errors in budget forecasts, forecasting authorities should be linked to movements in exogenous variables in the economy. Moreover, the government should avoid making any deliberate effort to under/overestimate revenues/expenditures (i) to give themselves enough room to maneuver with regard to unanticipated shortages/excess, or (ii) to prevent potential public reactions before the operation of the budget provided they were informed earlier about the potential budget deficit, tax increase, etc. 


\section{References}

Allan, C.M. (1965). Fiscal Marksmanship, 1951-63. Oxford Economic Papers, 17(2), 317-327.

Asher, M.G. (1977). Fiscal Marksmanship in Singapore, 1966 to 1974-75. Suara Ekono'd, 14, 11-22.

Asher, M.G. (1978). Accuracy of Budgetary Forecasts of Central Government, 1967-68 to 1975-76. Economic and Political Weekly, 13(8), 423-432.

Auld, D.A.L. (1970). Fiscal Marksmanship in Canada. Canadian Journal of Economics, 3(3), 507-511.

Bagdigen, M. (2005). An Empirical Analysis of accurate budget Forecasting in Turkey. Dogus Universitesi Dergisi, 6(2), 190-201.

Bhattacharya, B.B., and Kumari, A. (1988). Budget Forecasts of Central Government Revenue and Expenditure: A Test of Rational Expectation. Economic and Political Weekly, 23(26), 1323-1327

Bird, R.M. (1970). Taxation and Development. Cambridge, MA: Harvard University Press.

Chakrabarty, T.K., and Varghese, W. (1982). The Government of India's Budget Estimation: An Analysis of the Error Components. Reserve Bank of India Occasional Papers, 3(2).

Chakraborty, L.S., and Sinha, D. (2008). Budgetary forecasting in India: Portioning Errors and Testing for Rational Expectations. Working Paper No. 2008(7538), MPRA.

Chand, M. (1962). A Note on Under-Estimation in the Indian Central Budget. Indian Journal of Economics, 43.

Davis, J. M. (1980). Fiscal Marksmanship in the United Kingdom, 1951-78. Manchester School of Economics E Social Studies, 48(2), 187-202.

Lovell, M.C. (1986). Tests of the Rational Expectations Hypothesis. American Economic Review, 76(1), 110-124. 
Morrison, R.J. (1986). Fiscal Marksmanship in the United States: 1950-83. Manchester School of Economic and Social Studies, 54(3), 322-333.

Muth, J.F. (1961). Rational Expectations and the Theory of Price Movements. Econometrica, 29, 315-335.

Pindyck, R.S., and Rubenfield, D.L. (1998). Economic Models and Economic Forecasts. $4^{\text {th }}$ ed., McGraw-Hill.

Prest, A.R. (1961). Errors in Budgeting in the UK. British Tax Review, 30-43.

Prest, A.R. (1975). Public Finance in Developing Countries. London: Weidenfeld and Nicolson.

Rabushka, A. (1976). Value for Money: The Hong Kong Budgetary Process. Stanford: Hoover Institution Press.

Theil, H. (1958). Economic Forecasts and Policy. Amsterdam: North Holland.

Theil, H. (1966). Applied Economic Forecasting. Amsterdam: North Holland. 


\section{Appendix}

Table 1: Revenue and Capital Receipts in Revenue Account

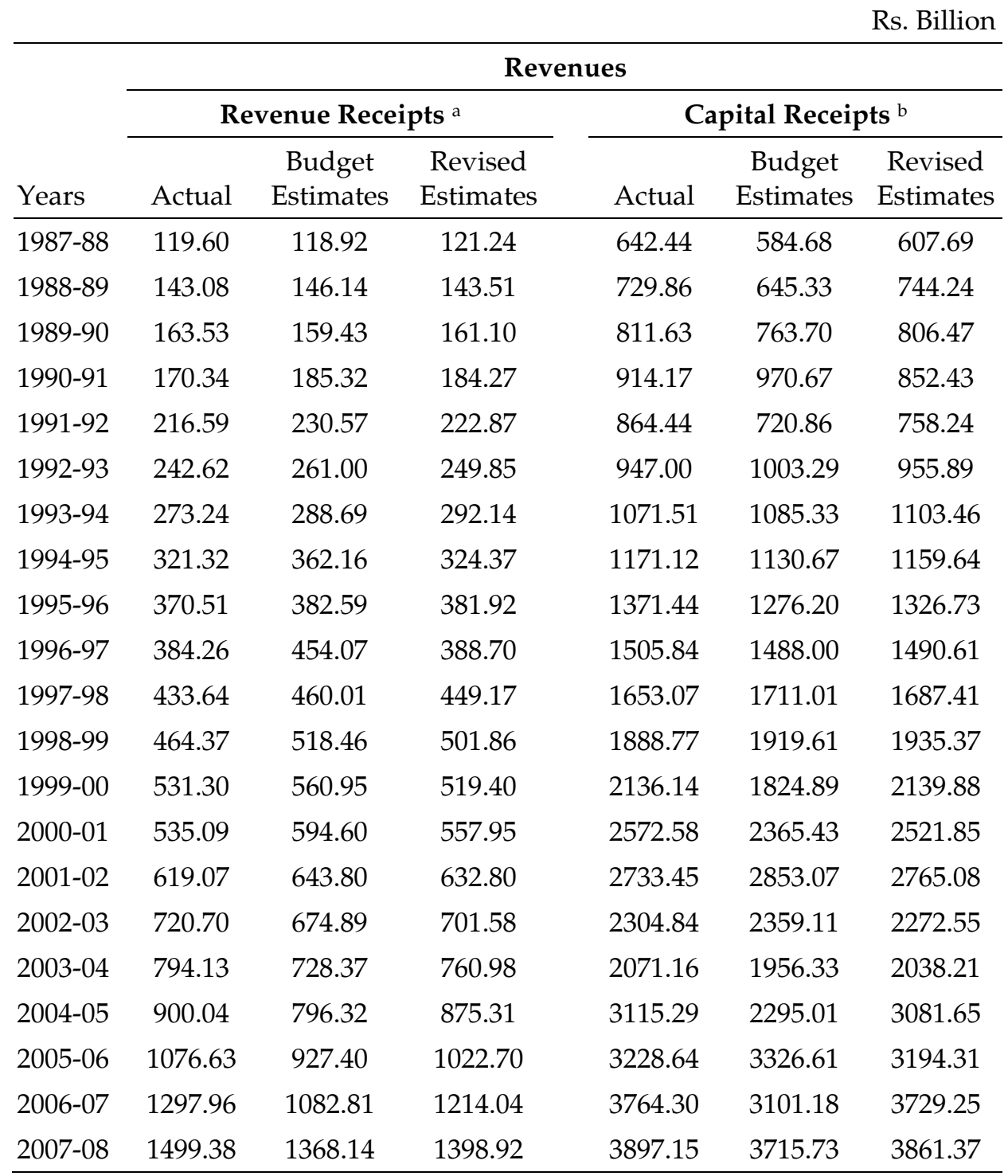

a It includes tax and non-tax revenues.

b It includes total federal internal gross receipts and loans. 
Table 2: Revenue and Capital Receipts in Expenditure Account

Rs. Billions

\begin{tabular}{|c|c|c|c|c|c|c|}
\hline \multirow[b]{3}{*}{ Years } & \multicolumn{6}{|c|}{ Expenditures } \\
\hline & \multicolumn{3}{|c|}{ Revenue Expenditures a } & \multicolumn{3}{|c|}{ Capital Expenditures ${ }^{b}$} \\
\hline & Actual & $\begin{array}{l}\text { Budget } \\
\text { Estimates }\end{array}$ & $\begin{array}{l}\text { Revised } \\
\text { Estimates }\end{array}$ & Actual & $\begin{array}{l}\text { Budget } \\
\text { Estimates }\end{array}$ & $\begin{array}{c}\text { Revised } \\
\text { Estimates }\end{array}$ \\
\hline $1987-88$ & 147.54 & 134.63 & 146.23 & 51.15 & 57.42 & 54.25 \\
\hline $1988-89$ & 163.09 & 163.06 & 159.48 & 47.03 & 41.90 & 47.99 \\
\hline $1989-90$ & 165.24 & 166.10 & 174.02 & 57.18 & 59.86 & 57.78 \\
\hline $1990-91$ & 189.28 & 185.48 & 184.03 & 70.86 & 55.06 & 59.86 \\
\hline 1991-92 & 211.69 & 203.49 & 213.04 & 114.40 & 90.62 & 101.60 \\
\hline $1992-93$ & 248.54 & 234.37 & 249.30 & 86.14 & 94.07 & 84.17 \\
\hline 1993-94 & 268.03 & 272.46 & 286.03 & 96.30 & 88.92 & 99.40 \\
\hline 1994-95 & 315.71 & 316.14 & 317.23 & 106.05 & 108.32 & 106.83 \\
\hline $1995-96$ & 382.67 & 364.47 & 379.66 & 124.20 & 115.14 & 110.68 \\
\hline $1996-97$ & 414.45 & 419.42 & 415.56 & 135.38 & 138.57 & 134.60 \\
\hline $1997-98$ & 466.50 & 476.93 & 470.23 & 125.90 & 126.61 & 129.93 \\
\hline 1998-99 & 529.03 & 515.96 & 494.23 & 156.98 & 160.91 & 149.70 \\
\hline 1999-00 & 604.37 & 553.91 & 585.12 & 137.07 & 151.51 & 151.74 \\
\hline 2000-01 & 612.68 & 604.02 & 601.71 & 95.38 & 90.32 & 96.13 \\
\hline 2001-02 & 694.45 & 662.61 & 697.68 & 254.28 & 173.47 & 259.22 \\
\hline $2002-03$ & 705.84 & 647.33 & 709.18 & 155.41 & 121.45 & 152.00 \\
\hline 2003-04 & 769.70 & 704.48 & 773.17 & 122.99 & 123.25 & 125.35 \\
\hline 2004-05 & 833.82 & 786.25 & 837.42 & 150.65 & 122.13 & 149.02 \\
\hline 2005-06 & 1068.50 & 961.10 & 1072.22 & 123.01 & 132.55 & 124.14 \\
\hline 2006-07 & 1230.28 & 1115.94 & 1234.15 & 131.11 & 137.82 & 130.33 \\
\hline 2007-08 & 1767.56 & 1353.66 & 1771.56 & 148.59 & 155.37 & 149.13 \\
\hline
\end{tabular}

a This includes current expenditure and development expenditure on revenue account.

b This includes current expenditure and development expenditure on capital account. 